\title{
Formação de Conceitos por Crianças com Paralisia Cerebral: Um Estudo Exploratório sobre a Influência de Atividades Lúdicas
}

\author{
Concept Development by Children with Cerebral Palsy: \\ A Study about the Influence of Playful Activities
}

\author{
Ana Paula Martins Cazeiro*, ${ }^{*}, b$ \& José Fernando Bitencourt Lomônaco ${ }^{b}$ \\ ${ }^{a}$ Universidade Federal do Rio de Janeiro, Rio de Janeiro, Brasil \& ${ }^{b}$ Universidade de São Paulo, São Paulo, Brasil
}

\begin{abstract}
Resumo
O objetivo deste trabalho foi investigar a influência de atividades lúdicas no processo de formação de conceitos espontâneos por crianças com seqüelas de paralisia cerebral. Participaram da pesquisa sete crianças, que foram submetidas a um pré-teste de conceitos espontâneos, sessões individuais de atividades lúdicas que envolviam alguns dos conceitos avaliados e reaplicação do teste inicial a fim de avaliar o grau de desenvolvimento dos conceitos. Todas as crianças participantes desenvolveram ao menos um dos conceitos mais vivenciados nas sessões de atividades lúdicas, além de terem desenvolvido outros conceitos espontâneos não avaliados por meio dos testes.

Palavras-chave: Formação de conceitos; Paralisia cerebral; Jogos e brinquedos; Terapia ocupacional.
\end{abstract}

\begin{abstract}
The objective of this research was to investigate the influence of playful activities in the process of developing basic concepts by children with cerebral palsy. The subjects were seven children who have been submitted to a pre-test of basic concepts; individual sessions of playful activities, which involved some of the evaluated concepts; and a second administration of the initial test in order to assess the degree of learning of such concepts. Every child has learned at least one of the concepts involved in the sessions of playful activities. They have also learned other concepts not evaluated by basic concepts tests.

Keywords: Concept formation; Cerebral palsy; Games and toys; Occupational therapy.
\end{abstract}

É amplamente reconhecido que o desenvolvimento de conceitos espontâneos ocorre por meio do contato da criança com objetos e pessoas presentes em seu ambiente (Hartley, 1971; Vygotsky, 1934/2001). Por exemplo, ao colocar-se "debaixo" da mesa ou "em cima" da cadeira, a criança experimenta algumas relações espaciais entre seu próprio corpo e os objetos. Ao empilhar cubos, a criança observa as relações dos objetos entre si. Durante suas atividades diárias e suas atividades lúdicas, a criança sem deficiência tem muitas oportunidades de vivenciar este tipo de experiência.

Por outro lado, no cotidiano de crianças com deficiência, como é freqüente no caso de crianças com paralisia

\footnotetext{
* Endereço para correspondência: Faculdade de Medicina - CCS - UFRJ (Curso de Terapia Ocupacional). Caixa Postal 68004 - CEP 21944-970. Rio de Janeiro, RJ. E-mails: paulacazeiro@gmail.comejfblusp@terra.com.br Este artigo é uma versão resumida da Dissertação de Mestrado da primeira autora, apresentada ao Instituto de Psicologia da Universidade de São Paulo (2008), no Programa de Pós-Graduação em Psicologia - área de concentração Psicologia Escolar e do Desenvolvimento Humano, sob a orientação do segundo autor.
}

cerebral, pode-se observar uma privação de oportunidades para vivenciar algumas atividades cotidianas e lúdicas, comuns à maioria das crianças (Carvalho, 1998; Missiuna \& Pollock, 1991). Dado por aceito que é por meio destas atividades que as crianças desenvolvem espontaneamente seus conceitos, os autores deste trabalho se propuseram investigar se, e em que medida, o envolvimento de crianças com paralisia cerebral em atividades lúdicas poderia facilitar sua aquisição de conceitos espontâneos.

Antes, porém, de apresentar o método e os resultados deste trabalho, cabe tecer algumas considerações sobre cada um dos temas nele envolvidos: paralisia cerebral, atividade lúdica e conceitos espontâneos.

Paralisia Cerebral. A paralisia cerebral decorre de uma lesão não-progressiva no encéfalo imaturo, ocasionada antes, durante ou após o nascimento de uma criança. Esta lesão pode ocasionar alterações motoras, sensoriais, cognitivas, entre outras, dependendo da extensão da lesão e da área encefálica atingida (Carvalho, 1998; Silva, 1997).

Embora algumas pesquisas associem a paralisia cerebral a atrasos no desenvolvimento cognitivo (Pfeifer, 
1997; Rothman, 1987), outras afirmam que a criança com paralisia cerebral pode apresentar um desenvolvimento intelectual compatível com o de crianças da mesma faixa etária (Braga, 1995; Eagle, 1985; Vargha-Khadem, Isaacs, Werf, Robb, \& Wilson, 1992). Tal desenvolvimento é algumas vezes associado ao grau de comprometimento motor (Lamônica, Vito, Rouston, Withaker, \& Ribeiro, 2003; Pfeifer, 1997); todavia, Braga (1995) e Eagle (1985) observaram que aquisições no desenvolvimento cognitivo podem ser alcançadas mesmo por crianças com graves comprometimentos motores decorrentes da paralisia cerebral.

De acordo com Braga (1995), o desenvolvimento da criança com paralisia cerebral depende tanto de fatores orgânicos (como a localização e a extensão da lesão), quanto do contexto no qual a criança está inserida. Assim, diversos fatores têm sido associados ao seu desenvolvimento cognitivo: gravidade do quadro motor, convulsões, escolarização, interação familiar, indicadores socioeconômicos, neuroplasticidade, intervenção precoce e participação em atividades lúdicas (Braga, 1995; Lamônica et al., 2003; Silva, 1997; Vargha-Khadem et al., 1992). E é sobre a influência de atividades lúdicas que este trabalho se refere.

Atividades Lúdicas. Não obstante ser um tema bastante estudado, parece não haver consenso entre teóricos e pesquisadores da área quanto à definição de atividade lúdica. Neste trabalho, optamos pela conceituação de Ferland (2006), segundo a qual o que faz com que uma atividade seja lúdica é a atitude lúdica, sendo esta compreendida como “. . . uma atitude subjetiva em que o prazer, a curiosidade, o senso de humor e a espontaneidade se tocam; tal atitude se traduz por uma conduta escolhida livremente, da qual não se espera nenhum rendimento específico" (p. 18).

Se não existe consenso entre os autores quanto à definição de atividade lúdica, a concordância é geral no tocante a sua importância para o desenvolvimento da criança. Dentre os vários benefícios arrolados: permite a apropriação da realidade e o conhecimento dos objetos; favorece a formação de conceitos e o pensamento abstrato; desenvolve a coordenação motora e a linguagem; permite a resolução de problemas e a sensação de controle do ambiente; favorece a descoberta de si; estimula a socialização e a autonomia (Bruner, 1986; Carvalho, 1998; Ferland, 2006; Hartley, 1971; Piaget, 1945/1975; Vygotsky, 1976).

Tendo-se em vista os benefícios decorrentes das atividades lúdicas, alguns autores afirmam que a falta de oportunidades para brincar pode gerar danos secundários ao desenvolvimento da criança com algum tipo de deficiência. Além das limitações específicas decorrentes de sua deficiência, outras barreiras podem ser impostas às atividades lúdicas desta criança, tais como as barreiras ambientais (inadequação de parques e brinquedos, falta de tempo), as barreiras sociais (preconceitos) e aquelas impostas por seus cuidadores (superproteção, negligência) (Blanche, 2002; Missiuna \& Pollock, 1991).

Algumas pesquisas empíricas corroboram as discussões teóricas a respeito das barreiras enfrentadas pela criança com deficiência no que se refere às oportunidades para brincar (Carvalho, 1998; Ferland, 2006), e outras ratificam a importância da atividade lúdica para o desenvolvimento da criança com paralisia cerebral, observando que o oferecimento de oportunidades para brincar favorece a melhoria da coordenação motora, da cognição, da linguagem, da socialização, da atenção, do equilíbrio e do desempenho em atividades da vida diária (Lorenzini, 1999; Peres, 2004; Sparling, Walker, \& Singdahlsen, 1984).

Conceitos Espontâneos. Ainda que não exista concordância entre os estudiosos quanto à definição de conceito (Flavell, 1976), parece não haver discordância em aceitar que conceitos são representações mentais formadas pelos indivíduos ao longo de sua vida, no processo de interação com o meio. A discordância ocorre, todavia, quando se pergunta que formas tomam nossas representações mentais, decorrendo daí as diferentes teorias de conceitos. Neste trabalho, tais teorias não serão consideradas; o leitor interessado poderá consultar Lomônaco (1997).

Um outro aspecto sobre o qual existe consenso entre os teóricos é o de que os conceitos apresentam grandes diferenças entre si, podendo ser classificados em diferentes tipos (Flavell, 1976). Uma das mais aceitas classificações dos conceitos divide-os em espontâneos e científicos. Neste artigo, "conceito espontâneo" será considerado sinônimo de "conceito básico" que, segundo Hartley (1971), engloba conceitos de objetos (como flor e cadeira) e conceitos relacionais, que dizem respeito a relações quantitativas (como mais/menos), relações espaciais (dentro/fora) e relações temporais (antes/depois).

Os conceitos espontâneos são formados incidentalmente nas atividades cotidianas das pessoas; os científicos são frutos do estudo sistemático de uma área de conhecimento. De acordo com Vygotsky (1934/2001), há relações complexas entre eles, de modo que um exerce influência sobre o outro. Por um lado, para o ensino de determinados conceitos científicos, parte-se do pressuposto de que a criança possua um sistema de conceitos já elaborado por meio da experiência espontânea. Por outro lado, a formação de conceitos científicos influencia o desenvolvimento dos conceitos espontâneos.

Este tipo de relação só é possível porque eles se desenvolvem de maneiras distintas. O início do desenvolvimento dos conceitos espontâneos está vinculado à experiência com objetos reais. Estes conceitos têm por base os atributos comuns dos objetos e se caracterizam pela ausência de percepção consciente de suas relações (por exemplo, para a criança pequena, o conceito de triângulo pode incluir a cor e o tamanho do triângulo que faz parte de seus brinquedos de encaixe, embora tais 
características não façam parte do conceito científico de triângulo). A criança conhece o objeto e tem um conceito dele, mas não tem consciência do próprio conceito. Apenas relativamente tarde ela tomará consciência deste conceito, de sua definição verbal, bem como de sua aplicação em relações lógicas entre os conceitos. Assim, no que diz respeito aos conceitos espontâneos, a criança caminha do objeto para o conceito.

Já os conceitos científicos surgem de um processo de ensino organizado, que começa pelo estudo do próprio conceito, com a conscientização de suas características essenciais, sua definição verbal e sua aplicação em operações lógicas (no exemplo anterior, após a aprendizagem formal, a criança poderá apreender as características que definem o conceito de triângulo, qual seja: uma figura plana, fechada, formada por três lados e três ângulos). Assim, no desenvolvimento destes conceitos, a criança caminha do conceito para o objeto.

Devido a estas peculiaridades, numa mesma criança, estes conceitos se apresentam em diferentes níveis de desenvolvimento, revelando pontos fortes e fracos. Os conceitos espontâneos, por surgirem da experiência pessoal, apresentam como ponto forte a facilidade de serem aplicados em situações espontâneas e concretas. Contudo, por nunca terem sofrido uma formulação científica, apresentam dificuldades de operação consciente, de definição verbal e de aplicação em um nível não-concreto. Já os conceitos científicos podem ser formulados e definidos com maior facilidade, sendo mais facilmente utilizados de maneira intencional e na realização de operações lógicas. Entretanto, são pobres em experiência pessoal, de modo que sua fraqueza pode revelar-se em seu verbalismo e em sua falta de concretude, sendo dificilmente transferidos para situações do cotidiano.

Sobre este aspecto, Vygotsky (1934/2001) descreve uma pesquisa na qual crianças completavam frases que envolviam conceitos científicos ou espontâneos. $\mathrm{O}$ autor observou um nível mais elevado de pensamento no campo dos conceitos científicos que nos espontâneos. Argumenta que os maus resultados no que se refere aos conceitos espontâneos ocorrem porque, no teste, a criança é exigida a fazer de forma consciente e arbitrária o que ela faz todos os dias de forma espontânea e não arbitrária.

Investigações Empíricas. Dado a importância dos conceitos para o desenvolvimento cognitivo, muitos estudos vêm sendo realizados sobre seu processo de formação por crianças de diferentes faixas etárias. Alguns deles investigaram tal processo em sujeitos que apresentam algum tipo de deficiência: Scheuer (1993) e Spector (1979) apontam para a ocorrência de um atraso no desenvolvimento de conceitos por crianças com deficiência intelectual; Aguiar (2004), Bock (1994) e Penazzo (1994) mostram que a experiência lúdica, o treinamento de estratégias de categorização e a experiência motora, influenciam a formação de conceitos básicos por crianças com deficiência. Dentre estas, a pesquisa realizada por Aguiar (2004) é a que apresenta características mais próximas da pesquisa aqui realizada. $\mathrm{O}$ autor estudou a influência de um programa de jogos infantis no desenvolvimento de conceitos básicos por crianças com problemas de aprendizagem, utilizando o Teste de Conceitos Básicos de Boehm como instrumento de avaliação. Os resultados confirmaram a eficiência do programa de jogos para a formação destes conceitos.

Em nosso meio, poucos estudos investigaram a formação de conceitos espontâneos por crianças com seqüelas de paralisia cerebral. Na revisão de literatura feita pelos autores deste trabalho apenas dois estudos foram encontrados: o de Carabetti, Leme e Prieto (2005) e o de Lamônica et al. (2003).

Lamônica et al. (2003), ao realizarem provas de reconhecimento de figuras, observaram que as crianças sem deficiência apresentaram resultados superiores aos de crianças com paralisia cerebral. Estas tiveram maior dificuldade para reconhecer figuras de objetos não relacionados à vida diária, o que pode ter ocorrido pela falta de experiências com tais objetos. Também foi observado que as crianças com menor comprometimento motor apresentaram melhores resultados do que as com maior comprometimento.

Carabetti et al. (2005) investigaram a formação do conceito de número em dois sujeitos com paralisia cerebral. Verificou-se que o participante com quadro motor mais leve e melhor condição econômica não havia formado tal conceito, ao contrário do participante com um quadro motor mais grave e situação econômica menos privilegiada. As autoras acreditam que, para este aluno, a interação no ambiente familiar, a vivência de brincadeiras e a aprendizagem escolar parecem ter compensado a disfunção.

Enquanto a investigação de Lamônica et al. (2003) indica que o desenvolvimento de conceitos pode apresentar relação com o grau de comprometimento motor, o estudo de Carabetti et al. (2005) sugere que nem mesmo um grave comprometimento é fator impeditivo para o desenvolvimento conceitual. Por outro lado, ambos os estudos sugerem que as experiências cotidianas parecem exercer fortes influências sobre este processo. Esta é também uma das variáveis que o presente estudo se propõe a avaliar.

\section{Método}

A fim de avaliar o desenvolvimento de conceitos espontâneos pelas crianças com deficiência, foi utilizado o delineamento pré-teste/treinamento/pós-teste para um único grupo. Também foram realizados estudos de casos, nos quais foram incluídos: os resultados obtidos por cada criança no pré-teste e no pós-teste; os dados de dois questionários respondidos pelos responsáveis sobre o desenvolvimento e o cotidiano de cada criança; os dados do diário de campo, coletados por meio da técnica da observação participante. 


\section{Participantes}

Participaram desta pesquisa sete crianças com seqüelas de paralisia cerebral, com idades entre seis anos e 11 meses a dez anos e 11 meses, freqüentadoras de três instituições de reabilitação. Foram excluídas as crianças que apresentavam deficiência intelectual moderada ou profunda já diagnosticada e/ou deficiência visual e/ou auditiva que impossibilitasse a comunicação e a participação nas tarefas. Foi utilizado também como critério o resultado nos itens de instrução do Teste de Boehm, sendo incluídas oito crianças que responderam adequadamente a, ao menos, quatro das seis questões referentes a objetos do dia a dia.

Visto que uma das oito crianças deixou de freqüentar a instituição no período dos atendimentos (a única criança acompanhada em uma instituição particular de educação especial e de reabilitação), um total de sete crianças participou da pesquisa, com idade média de oito anos e sete meses. Cinco crianças são do sexo masculino e duas do sexo feminino. Duas crianças, N. e B., apresentam paralisia cerebral do tipo tetraparesia espástica (comprometimento motor e aumento do tônus muscular envolvendo de forma semelhante os quatro membros do corpo), três crianças, F., FR. e E., apresentam quadro de diparesia espástica (comprometimento motor e aumento do tônus mais evidentes nos membros inferiores do que nos membros superiores) e duas crianças, V. e L., apresentam diagnóstico de tetraparesia atetóide (movimentação involuntária e flutuação do tônus muscular envolvendo os quatro membros do corpo). As crianças N., F., B. e FR. foram acompanhadas em uma instituição filantrópica, na qual realizavam hidroterapia. V., E. e L. foram acompanhadas em uma clínica-escola de Terapia Ocupacional. Nenhuma das crianças conhecia a pesquisadora antes da avaliação inicial. Todas elas realizavam ou realizaram tratamentos adicionais em outras instituições. Além disso, F. freqüentava uma pré-escola comum; N. freqüentava uma pré-escola especial; FR. e B. estavam na $1^{\mathrm{a}}$ série e, E., na $3^{\text {a }}$ série de escolas comuns; V. e L. freqüentavam a $3^{\mathrm{a}}$ série comum com apoio de estagiária. Os pais de F. e L. haviam cursado o primeiro grau completo, enquanto que os pais das demais crianças apresentavam o primeiro grau incompleto ou haviam cursado apenas o ensino fundamental.

\section{Material}

O instrumento utilizado no pré-teste e no pós-teste foi uma adaptação do Teste de Conceitos Básicos de Boehm (BTBC), o qual foi escolhido por incluir conceitos básicos considerados fundamentais para as atividades cotidianas e escolares, bem como por ser um material de fácil aplicação, visto que a criança é solicitada a escolher, dentre três figuras, aquela que exemplifica um determinado conceito.

Boehm (1977) agrupou os conceitos em quatro categorias: espaço, quantidade, tempo e mistos, sendo a cate- goria mistos referente a conceitos que não pertencem a nenhuma das três primeiras categorias. Para fins desta pesquisa, foram selecionados 15 conceitos, sendo cinco de cada domínio conceitual, excluindo os da categoria mistos. Para orientar a escolha destes 15 conceitos, foram consultados professores de pré-escola, $1^{\mathrm{a}}$ e $2^{\mathrm{a}}$ séries do primeiro grau, que indicaram, em uma lista de 24 conceitos, aqueles que consideravam fáceis, médios ou difíceis para crianças entre seis e oito anos de idade.

A partir das respostas dos professores, foram escolhidos três conceitos considerados médios, um considerado fácil e um considerado difícil, para cada domínio conceitual, totalizando 15 conceitos. No domínio de quantidade foram selecionados os conceitos "metade", "quase" e "menos" (nível médio), "muitos" (nível fácil) e "tamanho médio" (nível difícil). No domínio de espaço, os conceitos escolhidos foram "em volta", "entre" e "centro" (nível médio), "debaixo" (nível fácil) e "lado direito" (nível difícil). Os conceitos selecionados para o domínio de tempo foram "cedo", “depois" e "nunca" (nível médio), "agora" (nível fácil) e "logo" (nível difícil). A Tabela 1 apresenta os conceitos e as respectivas questões do teste utilizado nesta pesquisa.

Visto que o BTBC destina-se originalmente a crianças sem deficiência, os desenhos do teste, bem como os dos itens de instrução, foram adaptados aos sujeitos desta pesquisa. Assim, levando-se em consideração que muitas crianças com paralisia cerebral apresentam também algum tipo de alteração na função visual, os desenhos do teste foram ampliados numa proporção de $75 \%$ e coloridos, visando facilitar sua visualização. Foram feitas alterações em algumas questões e figuras do teste, quando estas apresentavam ambigüidades.

No decorrer da pesquisa também foram elaborados dois questionários para serem respondidos pelos cuidadores das crianças participantes. Um dos questionários indagava acerca das experiências lúdicas da criança; o outro, incluía questões sobre o desenvolvimento e a participação da criança nas atividades familiares e comunitárias.

\section{Procedimento}

O Teste de Conceitos Básicos de Boehm adaptado foi aplicado a um grupo de 13 crianças do ensino infantil, freqüentadoras de uma creche pública (idade média: cinco anos e seis meses), visando avaliar as adaptações realizadas e fornecer um ponto de referência a partir do qual os resultados das crianças com paralisia cerebral pudessem ser situados.

As crianças com paralisia cerebral incluídas na pesquisa foram também avaliadas por meio do teste adaptado. Para cada questão do teste, eram mostrados três desenhos e a criança era solicitada a indicar o desenho que se relacionava ao conceito de interesse do pesquisador. Antes do início do teste, a criança era informada de que poderia mudar de opinião a respeito da resposta correta, sendo 
Tabela 1

Teste de Conceitos Básicos de Boehm Adaptado: Conceitos Avaliados, Itens de Instrução, Questões Envolvendo os Conceitos Incluídos na Pesquisa e Opções de Respostas

\begin{tabular}{|c|c|c|}
\hline Conceitos & Questões & Opções de resposta \\
\hline 1 - Inst. Sapato & Olhe o sapato, o chapéu e a meia. Qual é o sapato? & Sapato, chapéu e meia. \\
\hline 2 - Inst. Banana & Olhem as frutas. Me mostre a banana. & Maçã, pêra e banana. \\
\hline 3 - Inst. Carro & $\begin{array}{l}\text { Olhe as coisas em que se pode viajar. Me mostre } \\
\text { qual é o carro. }\end{array}$ & Barco, carro e avião. \\
\hline 4 - Inst. Mesa & Olhe os móveis. Qual é a mesa? & Cadeira, cômoda e mesa. \\
\hline 5 - Inst. Copo & Olhe a colher, o copo e a xícara. Qual é o copo? & Colher, copo e xícara. \\
\hline 6 - Inst. Cachorro & Veja os animais. Me mostre o cachorro. & Cachorro, gato e pássaro. \\
\hline $1-$ Depois & $\begin{array}{l}\text { Olhe as fotos da moça. Mostre a foto que a moça } \\
\text { tirou depois de cortar o cabelo. }\end{array}$ & $\begin{array}{l}\text { Moça com cabelo curto, com cabelo } \\
\text { comprido e cortando o cabelo. }\end{array}$ \\
\hline 2 - Centro & $\begin{array}{l}\text { Olhe o círculo e os quadrinhos. Qual é o quadrinho } \\
\text { que está no centro do círculo? }\end{array}$ & $\begin{array}{l}\text { Círculo e quatro quadrinhos em diferentes } \\
\text { locais em relação ao círculo. }\end{array}$ \\
\hline 3-Quase & $\begin{array}{l}\text { Olhe as garrafas com suco de morango. Qual suco } \\
\text { está quase acabando? }\end{array}$ & $\begin{array}{l}\text { Garrafa com suco pela metade, cheia } \\
\text { e quase vazia. }\end{array}$ \\
\hline 4-Em volta & $\begin{array}{l}\text { Veja as bolinhas e os quadrados. Mostre as bolinhas } \\
\text { que estão em volta do quadrado. }\end{array}$ & $\begin{array}{l}\text { Três quadrados, sendo um com bolinhas } \\
\text { em volta, um com bolinhas dentro e fora } \\
\text { e outro com bolinhas no interior. }\end{array}$ \\
\hline 5 - Cedo & $\begin{array}{l}\text { Veja as crianças indo à escola. Qual criança chegará } \\
\text { mais cedo à escola? }\end{array}$ & Três crianças e uma escola. \\
\hline 6-Nunca & $\begin{array}{l}\text { Olhe a maçã, a cadeira e a pizza. Mostre o que uma } \\
\text { criança nunca deve comer. }\end{array}$ & Maçã, cadeira e pizza. \\
\hline 7 - Metade & Olhe as pizzas. Mostre a pizza que tem metade. & $\begin{array}{l}\text { Pizza pela metade, pizza inteira e pizza } \\
\text { faltando apenas um pedaço. }\end{array}$ \\
\hline 8 - Lado direito & $\begin{array}{l}\text { Olhe os quadrinhos e a linha. Mostre o quadrinho } \\
\text { que está no lado direito. }\end{array}$ & Uma linha abaixo de três quadrados. \\
\hline 9 - Tam. Médio & Olhe os peixes. Mostre o peixe de tamanho médio. & Três peixes de tamanhos diferentes. \\
\hline $10-$ Menos & $\begin{array}{l}\text { Veja os pratos com os doces. De todos os pratos, } \\
\text { qual tem menos doces? }\end{array}$ & $\begin{array}{l}\text { Prato com três doces, prato com } 10 \text { doces } \\
\text { e prato com um doce. }\end{array}$ \\
\hline $11-$ Entre & Olhe os pássaros. Qual está entre os outros dois? & Três pássaros iguais, sobre uma linha. \\
\hline $12-$ Logo & $\begin{array}{l}\text { Olhe os carros que vão entrar no túnel. Mostre } \\
\text { o carro que vai entrar logo no túnel. }\end{array}$ & Um túnel e três carros. \\
\hline 13 - Debaixo & Olhe a mesa e as bolas. Qual está debaixo da mesa? & $\begin{array}{l}\text { Mesa com uma bola em cima, uma } \\
\text { embaixo e outra ao lado. }\end{array}$ \\
\hline 14 - Muitas & $\begin{array}{l}\text { Veja as caixas com as bolinhas. Qual a caixa que } \\
\text { tem muitas bolinhas? }\end{array}$ & $\begin{array}{l}\text { Caixa com quatro bolinhas, caixa vazia } \\
\text { e caixa com } 11 \text { bolinhas. }\end{array}$ \\
\hline 15 - Agora & $\begin{array}{l}\text { Veja as meninas e os pratos. Qual menina está } \\
\text { comendo agora? }\end{array}$ & $\begin{array}{l}\text { Menina colocando a colher na boca (com } \\
\text { prato e copo com alimentos pela metade), } \\
\text { menina com prato e copo vazios e menina } \\
\text { com prato e copo cheios. }\end{array}$ \\
\hline
\end{tabular}

Nota. "Inst." indica os itens de instrução.

válida sua última resposta. Cada pergunta era feita duas vezes e a criança indicava o desenho escolhido. A pesquisadora registrava a resposta em uma folha, mas não informava a criança sobre a ocorrência de acerto ou erro.

Estas crianças participaram, a seguir, de atendimentos individuais de Terapia Ocupacional, em sessões semanais de 50 minutos à uma hora cada, por quatro ou cinco meses, totalizando 16 atendimentos. Nestes atendimentos procurou-se criar condições para que a criança conseguisse brincar da maneira a mais autônoma possível. A pesquisadora brincava com a criança e exercia o papel de mediadora, enriquecendo a atividade lúdica e fornecendo ajuda quando necessário. Utilizava-se da linguagem verbal com o objetivo de estimular o desenvolvimento dos conceitos avaliados, de modo que estes eram nomeados quando se relacionavam com a situação vivenciada. Um trecho do diário de campo ajuda a ilustrar a dinâmica das atividades lúdicas (os conceitos envolvidos aparecem entre aspas):

V. escolheu brincar com os carimbos de peixes (dentre as opções: pescaria, massinha e quadro imantado). Foilhe indicado que, "antes", precisava molhar o carimbo na 
tinta para, "depois", carimbar o papel. Durante a brincadeira, a pesquisadora comentou que não gostaria de nadar naquele mar, pois havia "muitos" tubarões, havendo "mais" tubarões e "menos" peixes. V. riu e quis fazer mais tubarões. Foram também desenhados tubarões de outros tamanhos. V. quis recortar as figuras, necessitando de auxílio. V. escolheu em qual bacia, "pequena", "média" ou "grande", colocaria os peixes recortados. Começaram a pescar com a mãozinha de silicone (que gruda em papel, sendo utilizada como vara de pescar) e a pesquisadora nomeava o tamanho dos peixes pescados ("pequeno", "médio" ou "grande"). Havia uma competição entre a criança (que necessitava da ajuda da pesquisadora) e seu padrasto. Comparavam para ver quem havia pescado "mais" e "menos" peixes. O padrasto jogou a mãozinha na direção de V., dizendo que pescaria um peixe grande. Brincaram de acertar um no outro. A pesquisadora carimbou um tubarão na mão "direita" e um peixe na mão "esquerda" da criança, dizendo que deveria ter cuidado para que o tubarão não comesse o peixe. A criança riu. O padrasto levou as figuras para casa e improvisou, para a criança, uma varinha com barbante e fita crepe.

Para fins desta pesquisa, foi realizada uma seleção de atividades lúdicas que envolvem conceitos espontâneos e que, com ou sem adaptações e/ou ajuda de outras pessoas, podem ser realizadas por crianças com alterações motoras. Algumas destas atividades foram oferecidas às crianças participantes, sendo as atividades realizadas de acordo com o interesse delas. Assim, no início de cada sessão, a criança escolhia, dentre algumas atividades sugeridas pela pesquisadora, qual desejava realizar, mantendo-se a natureza voluntária da atividade lúdica.

Após o período de intervenção, as crianças participantes foram reavaliadas (pós-teste) por meio do mesmo instrumento utilizado no pré-teste, mantendo-se a mesma ordem de apresentação das questões.

Foram feitos registros, no diário de campo, de todas as atividades desenvolvidas em cada um dos atendimentos, incluindo-se a dinâmica da atividade lúdica, a participação da criança e de seu acompanhante, as dificuldades encontradas pela pesquisadora e as reflexões tecidas ao longo do estudo. Estes dados foram correlacionados aos resultados dos testes e às informações coletadas por meio dos questionários. Cada caso foi analisado individualmente e, em seguida, foi feita uma análise conjunta dos casos em questão.

\section{Resultados}

Os resultados do pré e do pós-teste foram analisados por meio de estatísticas descritivas e inferenciais. Adotou-se para os testes de hipóteses o nível de significância de $5 \%$ e se utilizou o programa computacional "SPSS 11.5 for Windows".

Na Tabela 2 são apresentados os resultados das crianças da creche (idade média: cinco anos e seis meses) e os resultados do pré-teste aplicado às crianças com paralisia cerebral (idade média: oito anos e nove meses).

Tabela 2

Comparação entre os Resultados no Teste de Boehm Adaptado Obtidos pelas Crianças da Creche e pelas Crianças com Paralisia Cerebral (Pré-teste)

\begin{tabular}{lccr}
\hline $\begin{array}{l}\text { Alunos X } \\
\text { Conceitos }\end{array}$ & $\begin{array}{c}\text { Crianças da } \\
\text { creche \% (A) }\end{array}$ & $\begin{array}{c}\text { Crianças da } \\
\text { pesquisa \% (B) }\end{array}$ & $\begin{array}{r}\text { Diferença } \\
\text { A-B\% }\end{array}$ \\
\hline 1 - Inst. Sapato & 100 & 85,7 & 14,3 \\
2 - Inst. Banana & 100 & 100 & 0 \\
3 - Inst. Carro & 100 & 100 & 0 \\
4 - Inst. Mesa & 100 & 85,7 & 14,3 \\
5 - Inst. Copo & 100 & 85,7 & 14,3 \\
6 - Inst. Cachorro & 100 & 100 & 0 \\
1 - Depois & 61,5 & 28,6 & 32,9 \\
2 - Centro & 84,6 & 42,8 & 41,8 \\
3 - Quase & 100 & 71,4 & 28,6 \\
4 - Em volta & 92,3 & 28,6 & 63,7 \\
5 - Cedo & 38,5 & 85,7 & $-47,2$ \\
6 - Nunca & 61,5 & 14,3 & 47,2 \\
7 - Metade & 69,2 & 42,8 & 26,4 \\
8 - Lado direito & 7,7 & 57,1 & $-49,4$ \\
9- Tam. Médio & 69,2 & 28,6 & 40,6 \\
10 - Menos & 23,1 & 28,6 & $-5,5$ \\
11 - Entre & 61,5 & 57,1 & 4,4 \\
12 - Logo & 100 & 71,4 & 28,6 \\
13 - Debaixo & 100 & 71,4 & 28,6 \\
14 - Muitas & 100 & 71,4 & 28,6 \\
15 - Agora & 100 & 71,4 & 28,6 \\
\hline
\end{tabular}

Nota. "Inst." indica os itens de instrução.

As crianças da creche apresentaram um maior número de acertos em quase todas as questões, com exceção das questões referentes aos conceitos de "lado direito", "cedo" e "menos". Contudo, das crianças da pesquisa que acertaram o conceito de "lado direito", duas não dominavam tal conceito em situações práticas e duas parecem ter acertado por acaso, pois erraram no pós-teste. A análise descritiva dos resultados mostra, no grupo de crianças da creche, o valor máximo 13, a média 9 , a mediana 9 e o desvio padrão 4; o grupo de crianças com paralisia cerebral apresentou valores menores (valor máximo: 6; média: 4; mediana: 4; desvio padrão: 2). Em resumo, as crianças da creche apresentaram valores menos homogêneos em relação à média, comparativamente ao grupo de crianças com paralisia cerebral, cujos resultados se apresentaram mais homogêneos. Foi realizado o teste " $t$ Student" para amostras independentes, o qual indicou que há diferença significante entre os resultados dos grupos $(t=5,251 ; p=0,000)$.

A Tabela 3 apresenta os resultados das crianças com seqüelas de paralisia cerebral no início (pré-teste) e no final da pesquisa (pós-teste).

É possível observar que os maiores aumentos no número de respostas corretas ocorreram nas questões refe- 
Tabela 3

Comparação entre os Resultados do Teste de Boehm Adaptado Obtidos no Pré-teste e no Pós-teste pelas Crianças com Paralisia Cerebral

\begin{tabular}{lccc}
\hline $\begin{array}{l}\text { Crianças / } \\
\text { conceitos }\end{array}$ & $\begin{array}{c}\text { Pré-teste (\%) } \\
\text { A }\end{array}$ & $\begin{array}{c}\text { Pós-teste (\%) } \\
\text { B }\end{array}$ & $\begin{array}{c}\text { Diferença } \\
\text { (B - A) }\end{array}$ \\
\hline 1 - Inst. Sapato & 85,7 & 100 & 14,3 \\
2 - Inst. Banana & 100 & 100 & 0 \\
3 - Inst. Carro & 100 & 100 & 0 \\
4 - Inst. Mesa & 85,7 & 85,7 & 0 \\
5 - Inst. Copo & 85,7 & 100 & 14,3 \\
6 - Inst. Cachorro & 100 & 100 & 0 \\
1 - Depois & 28,6 & 57,1 & 28,5 \\
2 - Centro & 42,8 & 71,4 & 28,6 \\
3 - Quase & 71,4 & 71,4 & 0 \\
4 - Em volta & 28,6 & 57,1 & 28,5 \\
5 - Cedo & 85,7 & 71,4 & $-14,3$ \\
6 - Nunca & 14,3 & 14,3 & 0 \\
7 - Metade & 42,8 & 42,8 & 0 \\
8 - Lado direito & 57,1 & 28,6 & $-28,5$ \\
9 - Tam. Médio & 28,6 & 28,6 & 0 \\
10 - Menos & 28,6 & 85,7 & 57,1 \\
11 - Entre & 57,1 & 42,8 & $-14,3$ \\
12 - Logo & 71,4 & 57,1 & $-14,3$ \\
13 - Debaixo & 71,4 & 100 & 28,6 \\
14 - Muitas & 71,4 & 71,4 & 0 \\
15 - Agora & 71,4 & 71,4 & 0 \\
\hline
\end{tabular}

Nota. "Inst." indica os itens de instrução. rentes aos conceitos de "menos" (57,1\% a mais de respostas corretas), "depois", "em volta", "centro" e "debaixo" (28,6\%). As questões correspondentes aos conceitos de "cedo", "entre" e "logo" tiveram um decréscimo no número de respostas corretas (-14,3\%), assim como "lado direito" (-28,5\%), o que indica que, no pré-teste, alguns acertos possam ter ocorrido por acaso. A análise descritiva indicou que as medidas de posição foram iguais para as variáveis em estudo (mínimo: 1; média: 4; mediana: 4). O valor máximo foi igual a 6 no pré-teste e igual a 7 no pós-teste. A medida de variabilidade também foi igual (desvio padrão: 2). O teste " $t$-Student" para amostras emparelhadas revela não haver diferença significante entre os resultados do pré-teste e do pós-teste $(t=-1,131$; $p=0,277)$.

As anotações do diário de campo foram utilizadas para complementar estes dados. A partir de tais anotações foi possível identificar os conceitos espontâneos mais vivenciados por cada criança participante. Considerouse razoável supor que a vivência com cada conceito constitui uma variável crucial para o seu desenvolvimento, visto que, de acordo com Hartley (1971), a criança necessita de experiências variadas e repetidas para o desenvolvimento de conceitos espontâneos. Por este motivo, foram analisados os resultados obtidos nas questões do teste referentes aos três conceitos mais vivenciados nas sessões de atividades lúdicas oferecidas a cada criança. Tais observações são apresentadas na Tabela 4.

Tabela 4

Conceitos Mais Vivenciados nas Sessões de Atividades Lúdicas, Respostas das Crianças no Pré-teste e no Pós-teste e Diferença do Número de Acertos

\begin{tabular}{lccccc}
\hline Sujeito & Conceito & \% de sessões & $\begin{array}{c}\text { Pré-teste } \\
\text { A }\end{array}$ & $\begin{array}{c}\text { Pós-teste } \\
\text { B }\end{array}$ & $\begin{array}{c}\text { Diferença do no. } \\
\text { de acertos (B-A) }\end{array}$ \\
\hline N. & Debaixo & 62,5 & 0 & 1 & 3 \\
& Depois & 50 & 0 & 1 & 1 \\
F. & Centro & 37,5 & 0 & 1 & 1 \\
& Lado direito & 92,3 & 1 & 1 & 1 \\
B. & Menos & 76,9 & 0 & 1 & 1 \\
& Debaixo & 30,8 & 1 & 1 & \\
FR. & Debaixo & 57,1 & 0 & 0 & 1 \\
& Depois & 28,6 & 0 & 0 & 1 \\
V. & Centro & 14,3 & 0 & 1 & \\
& Lado direito & 81,8 & 1 & 0 & \\
& Centro & 63,3 & 0 & 0 & \\
E. & Depois & 45,4 & 0 & 0 & 1 \\
& Tamanho médio & 100 & 0 & 1 & \\
L. & Menos & 100 & 0 & 0 & \\
& Depois & 80 & 0 & 1 & \\
& Muitas & 91,7 & 0 & 1 & \\
\hline
\end{tabular}


Conforme é possível observar, todas as crianças participantes da pesquisa desenvolveram ao menos um dos conceitos espontâneos mais vivenciados no decorrer das sessões. Além disso, alguns conceitos não avaliados por meio do teste também foram incluídos nas atividades lúdicas; por meio dos diários de campo, foi possível observar o desenvolvimento de alguns destes.

De modo geral, N. acertou, no pós-teste, as questões referentes aos conceitos de "debaixo", "depois", "centro" e "menos", que havia errado no pré-teste. F., além de ter acertado o conceito de "menos", no pós-teste, também desenvolveu, conforme observado durante as atividades lúdicas, os conceitos de "mais", "lado", "lado direito" e "lado esquerdo". B. acertou, no pós-teste, as questões referentes aos conceitos "debaixo" e "menos", mas também se observou o desenvolvimento dos conceitos de "grande" e "pequeno". FR. acertou no pós-teste os conceitos de "centro", "entre" e "em volta"; também evoluiu no uso dos conceitos de "menos" e "lado direito" em situações espontâneas. V. acertou no pós-teste os conceitos de "depois" e "em volta", mas também parece ter evoluído no desenvolvimento do conceito de "menos", nas atividades lúdicas. E. acertou, no pós-teste, as questões referentes aos conceitos de "muitas", "agora" e "menos". L., por sua vez, acertou os conceitos de "em volta", "tamanho médio" e "centro".

Além do desenvolvimento de conceitos espontâneos, as anotações do diário de campo permitiram observar que as sessões de atividades lúdicas favoreceram outros aspectos do desenvolvimento das crianças participantes, tais como: o uso de ambas as mãos, visto que algumas crianças evitavam, no início da pesquisa, o uso do membro superior mais afetado; a coordenação motora, notandose uma redução do grau de assistência para as crianças que necessitavam de ajuda; o comportamento, observando-se um maior respeito aos limites impostos pela pesquisadora e às regras dos jogos; a participação nas atividades lúdicas, havendo um engajamento em atividades mais complexas. A mãe de N. relatou que ele voltou a se interessar pelos brinquedos, visto que antes deixava de brincar para assistir à televisão.

\section{Discussão}

Segundo Vygotsky (1998), no processo de desenvolvimento do ser humano ocorre uma interação entre os aspectos biológicos e culturais, de modo que os seus processos psíquicos elementares estão pautados no substrato neural, enquanto que suas funções mais complexas têm uma influência mais significativa do contexto sociocultural do qual faz parte. Desta afirmação podemos extrair duas reflexões. Primeira, é de se esperar que a criança com deficiência decorrente de uma lesão no sistema nervoso central apresente algumas dificuldades resultantes diretamente da lesão encefálica. Uma segunda reflexão que podemos fazer diz respeito ao fato de que a capacidade cognitiva não decorre simplesmente do substrato neural, mas também, ou principalmente, das condições concretas de vida de cada indivíduo. Por isso, a lesão encefálica simplesmente não é capaz de explicar a totalidade do desenvolvimento da criança com paralisia cerebral, visto que grande parte deste decorre das oportunidades que o meio social lhe oferece. Vygotsky (1983/ 1997) parece concordar com esta afirmação, pois declara que é no desenvolvimento cultural que se abre um caminho infinitamente maior de possibilidades para a compensação da deficiência.

Não obstante tais considerações, ainda são poucas as pesquisas que investigam o impacto de fatores ambientais, tais como a estimulação por meio de atividades lúdicas, sobre o desenvolvimento da criança com paralisia cerebral. Na prática clínica, frequentemente, as dificuldades da criança com este tipo de deficiência são atribuídas a causas primárias, decorrentes da lesão encefálica, negligenciando o fato de que as dificuldades escolares e a própria deficiência intelectual podem ser de origem secundária, resultantes das dificuldades para explorar o ambiente (Peres, 2004) ou da falta de estimulação ambiental (Ferland, 2006).

Nesta pesquisa, os dados obtidos por meio dos questionários indicaram, tal como descrito por Carvalho (1998) e Ferland (2006), algumas barreiras para as atividades lúdicas das crianças participantes. Além da falta de acesso a atividades lúdicas variadas e da escassez de oportunidades para relacionar-se com crianças sem deficiência, a própria incapacidade motora mostrou-se um fator que limita a realização de tais atividades pelas crianças com deficiência. Apesar destas barreiras, as observações no diário de campo indicaram que todas as sete crianças, ao serem estimuladas a participar das atividades lúdicas, demonstraram atitude lúdica e motivação, tal como mencionado por Blanche (2002) e Ferland (2006).

Segundo Vygotsky (1934/2001), o desenvolvimento de conceitos espontâneos se dá por meio do contato da criança com os objetos e com as pessoas. Desta forma, tal como descrito por Hartley (1971), em momentos de atividades lúdicas ou em situações cotidianas, a criança vai formando seus conceitos espontâneos de quantidade, tempo e espaço. Contudo, a criança com deficiência pode ter poucas oportunidades de vivenciar este tipo de situação, pois a incapacidade dificulta a exploração ativa do ambiente - ela pode precisar de ajuda para isso.

Além da dificuldade na manipulação de objetos e da restrição na participação de atividades lúdicas, a criança com paralisia cerebral muitas vezes não participa de atividades familiares como uma criança sem deficiência. Esta criança explora ativamente o ambiente, acompanha seus pais por todos os cômodos da casa, observando de onde os objetos são retirados e onde são guardados, vendo como as coisas são naturalmente categorizadas: por exemplo, a comida é guardada em um armário, as panelas em outro, as diferentes peças do vestuário são distribuídas de acor- 
do com o seu uso em diferentes gavetas. Este tipo de atividade de discriminação e classificação favorece, de forma espontânea, a categorização e a formação de conceitos. Já a criança com deficiência, em muitos casos, permanece passiva, apenas recebendo os objetos necessários para seus cuidados pessoais. Elas podem não ter oportunidades de ver como as coisas são arrumadas nos armários e nas gavetas, e nem sempre contam com um suporte familiar estimulante.

Para Jurdi (2001), muitos familiares têm dificuldades em estabelecer trocas com a criança com deficiência porque não têm expectativas positivas sobre o seu desenvolvimento. Na prática clínica, encontramos até mesmo pais que não conversam com os seus filhos com deficiência, pois pensam que eles não compreendem nada. E, no entanto, a comunicação é fundamental para o desenvolvimento de qualquer criança, sendo por meio de relações sociais concretas, como aquelas estabelecidas em momentos de atividades lúdicas e atividades cotidianas, que um indivíduo começa a se apropriar do conhecimento e da linguagem.

Deste modo, diferentes condições da vida da criança com deficiência podem interagir para dificultar seu desenvolvimento cognitivo: a incapacidade motora, que dificulta a exploração do meio; a redução da comunicação com seus pais; a falta de oportunidades para brincar e participar de tarefas cotidianas. Assim, apesar de sabermos que a criança com paralisia cerebral possa ter uma deficiência intelectual de origem orgânica, devemos averiguar se o atraso no desenvolvimento conceitual não é decorrente da privação de experiências, de modo que este atraso não seja inquestionavelmente atribuído a um déficit cognitivo.

Além disso, o déficit na formação de conceitos espontâneos pode acarretar em dificuldades na aprendizagem escolar, visto que, tal como descrito por Vygotsky (1934/ 2001), a aprendizagem de conceitos científicos ocorre por mediação dos conceitos espontâneos. Em adição, algumas crianças com deficiência têm seus objetivos educacionais e terapêuticos subestimados, o que reduz ainda mais suas possibilidades de desenvolvimento (Jurdi, 2004). De acordo com Vygotsky (1983/1997), muitos educadores limitam a priori o aprendizado da criança com deficiência, por acreditar que ela não poderá aprender nada além.

Ao compararmos os resultados do pré-teste com os resultados obtidos por crianças sem deficiência, percebemos que, com exceção de F., as crianças da pesquisa apresentavam um atraso no desenvolvimento dos conceitos avaliados. Não podemos, contudo, nos acomodar na crença de que, por se tratar de crianças com deficiência, este atraso já era esperado, pois é este tipo de pensamento que nos leva a limitar a priori as suas possibilidades de desenvolvimento. Embora não possamos excluir a possibilidade de que algum dos participantes apresentasse algum nível de deficiência intelectual de origem orgâni- ca, não podemos justificar o mau desempenho no teste pela alegação de que tais crianças não conseguem aprender, pois, como observado no final da pesquisa, todas as crianças desenvolveram ao menos um dos conceitos mais vivenciados. Se elas se mostraram capazes de desenvolver tais conceitos, podemos nos perguntar se o fato de não os terem desenvolvido antes não seria decorrente da falta de oportunidades para isso.

Embora algumas crianças tenham acertado, no pósteste, questões referentes a conceitos pouco vivenciados, a aprendizagem parece ter ocorrido, principalmente, em relação aos conceitos mais vivenciados durante as sessões de atividades lúdicas. Este dado sugere que a oportunidade para vivenciar cada conceito repetidas vezes seja um fator crucial no desenvolvimento de conceitos básicos por crianças com paralisia cerebral. É possível, portanto, que o não desenvolvimento de muitos dos conceitos avaliados possa ser atribuído ao número limitado de sessões, o que representou uma vivência insuficiente com cada um deles. Tal hipótese é condizente com as discussões de Hartley (1971), para o qual, no desenvolvimento de conceitos espontâneos a criança necessita de uma variedade de experiências concretas com os objetos e pessoas, e oportunidades para repeti-las quantas vezes forem necessárias.

Por outro lado, outros conceitos que não foram avaliados também foram incluídos nas atividades. Esta inclusão ocorreu principalmente pelo fato de que os conceitos espontâneos utilizados são do tipo relacional, que só adquirem sentido se considerarmos sua relação com outros conceitos. As observações realizadas no decorrer dos atendimentos e registradas no diário de campo possibilitaram perceber que as crianças desenvolveram alguns destes conceitos que, embora não tenham feito parte da pesquisa, foram observados nas atividades lúdicas. Os dados do diário de campo também serviram para respaldar as informações obtidas por meio do teste de conceitos, visto a dificuldade encontrada em alguns momentos no que se refere à aplicação deste: algumas crianças acertaram itens no pré-teste e erraram no pós-teste, o que sugere acertos por acaso; outras responderam de maneira correta à questão, mas não pareciam dominar o mesmo conceito em situações práticas; outras, ao contrário, conheciam alguns conceitos em situações práticas, mas não acertaram as questões a eles referentes no teste; outras, ainda, demonstraram dúvidas ao indicar a resposta que julgavam correta, o que sugere que o conceito estivesse em fase de desenvolvimento.

A disparidade observada entre alguns dados do teste e anotações do diário de campo chama a atenção para uma questão que envolve a utilização de testes de conceitos. Visto que os conceitos aqui investigados são do tipo espontâneo, há uma dificuldade no seu emprego em situações que exijam o seu uso consciente (Vygotsky, 1934/ 2001). Deste modo, os relatos do diário de campo, que descrevem situações que ocorreram durante as ativida- 
des lúdicas, parecem ter apontado de maneira mais adequada a evolução da criança do que o Teste de Conceitos Básicos de Boehm, que exige um emprego consciente de cada conceito. Talvez este tipo de teste seja mais adequado para avaliar conceitos já dominados pela criança, que já se tornaram conscientes, não sendo sensível o suficiente para avaliar conceitos espontâneos em fase de desenvolvimento. Além disso, uma outra limitação do teste utilizado encontra-se no fato de que este apresenta cada conceito em apenas uma situação; sendo que a criança pode dominar o conceito em algumas situações, mas não em outras.

Por fim, algumas limitações da pesquisa podem ter influenciado os resultados, quais sejam: o pouco tempo disponível para os atendimentos, que impossibilitou vivenciar de forma semelhante todos os conceitos avaliados; a realização do pré-teste no contato inicial com a criança, e os múltiplos papéis da pesquisadora. Diante destas limitações, coloca-se a necessidade de que sejam realizadas outras investigações sobre o assunto, bem como a necessidade de um teste de conceitos básicos que envolva um mesmo conceito em diferentes situações e no qual a criança os aplique espontaneamente, como em situações lúdicas.

Com a realização desta pesquisa buscamos ressaltar a importância de fornecer oportunidades para que a criança com deficiência vivencie situações comuns a qualquer criança, visto que é nestas atividades cotidianas e lúdicas que se dá a formação dos conceitos espontâneos, essenciais para as aprendizagens futuras. Além disso, salientamos a importância da comunicação entre a criança e o adulto em tais atividades, sendo a linguagem fundamental para a apropriação do conhecimento e para o desenvolvimento cognitivo da criança.

\section{Referências}

Aguiar, J. S. (2004). Educação inclusiva: Jogos para o ensino de conceitos. Campinas, SP: Papirus.

Blanche, E. I. (2002). Fazer junto com - não fazer para: A recreação e as crianças portadoras de paralisia cerebral. In L. D. Parham \& L. S. Fazio, A recreação na terapia ocupacional pediátrica (pp. 202-218). São Paulo, SP: Santos.

Bock, M. A. (1994). Acquisition, maintenance and generalization of a categorization strategy by children with autism. Journal of Autism and Developmental Disorders, 24(1), $39-51$.

Boehm, A. E. (1977). Teste de conceitos básicos de Boehm $(B T B C)$. Rio de Janeiro, RJ: Centro Editor de Psicologia Aplicada.

Braga, L.W. (1995). Cognição e paralisia cerebral: Piaget e Vygotsky em questão. Salvador, BA: SarahLetras.

Bruner, J. S. (1986). Juego, pensamiento y lenguaje. Perspectivas, 15(1), 79-85.

Carabetti, S. C., Leme, M. I. S., \& Prieto, R. G. (2005). A construção do conceito de número em dois alunos com paralisia cerebral. Boletim de Psicologia, 55(122), 23-41.
Carvalho, L. M. G. (1998). As atividades lúdicas e a criança com paralisia cerebral: O jogo, o brinquedo e a brincadeira no cotidiano da criança e da família. Dissertação de Mestrado não-publicada, Faculdade de Educação Física, Universidade Estadual de Campinas, SP.

Eagle, R. S. (1985). Deprivation of early sensoriomotor experience and cognition in the severely involved cerebralpalsied child. Journal of Autism and Developmental Disorders, 15(3), 269-283.

Ferland, F. (2006). O modelo lúdico: O brincar, a criança com deficiência física e a terapia ocupacional. São Paulo, SP: Roca.

Flavell, J. F. (1976). O desenvolvimento de conceitos. In P. H. Mussen (Ed.), Carmichael Psicologia da Criança (Vol. 6, pp. 1-13). São Paulo, SP: Editora da Universidade de São Paulo.

Hartley, R. E. (1971). Play, the essential ingredient. Childhood Education, 48(2), 80-84.

Jurdi, A. P. S. (2001). Atividade lúdica: Uma atividade criativa. Temas sobre Desenvolvimento, 10(56), 46-50.

Jurdi, A. P. S. (2004). O processo de inclusão escolar do aluno com deficiência mental: A atuação do terapeuta ocupacional. Dissertação de Mestrado não-publicada, Instituto de Psicologia, Universidade de São Paulo, SP.

Lamônica, D. A. C., Vito, L. P. M., Rouston, J. C., Withaker, M. E., \& Ribeiro, L. M. (2003). Avaliação do aspecto semântico da linguagem em paralíticos cerebrais. Salusvita, 22(2), 229-237.

Lomônaco, J. F. B. (1997). A natureza dos conceitos: Visões psicológicas. Tese de Livre-Docência não-publicada, Instituto de Psicologia, Universidade de São Paulo, SP

Lorenzini, M. V. (1999). Brincando no ambiente natural: Uma contribuição para o desenvolvimento sensório-motor da criança portadora de paralisia cerebral. Tese de Doutorado não-publicada, Faculdade de Educação Física, Universidade Estadual de Campinas, SP.

Missiuna, C., \& Pollock, N. (1991). Play deprivation in children with disabilities: The role of the Occupational Therapist in preventing secondary disability. American Journal of Occupational Therapy, 45(10), 882-888.

Penazzo, A. A. (1994). Um estudo sobre a aprendizagem de conceitos por crianças deficientes mentais moderados. Tese de Doutorado não-publicada, Instituto de Psicologia, Universidade de São Paulo, SP.

Peres, R. C. N. C. (2004). O lúdico no desenvolvimento da criança com paralisia cerebral espástica. Revista Brasileira de Crescimento e Desenvolvimento Humano, 14(3), 37-49.

Pfeifer, L. I. (1997). Comprometimento motor e aquisição de habilidades cognitivas em crianças portadoras de paralisia cerebral. Temas sobre Desenvolvimento, 6(31), 4-13.

Piaget, J. (1975). A formação do símbolo na criança. Rio de Janeiro, RJ: Zahar. (Original work published 1945)

Rothman, J. G. (1987). Understanding order of movement in youngsters with cerebral palsy. Perceptual and Motor Skills, 65, 391-397.

Scheuer, C. I. (1993). Produção de relações espaciais em deficientes mentais leves: Uso de figuras. Temas sobre Desenvolvimento, 2(11), 15-22.

Silva, R. K. (1997). A neuroplasticidade no desenvolvimento de crianças com paralisia cerebral. Temas sobre Desenvolvimento, 34(6), 7-13. 
Sparling, J. W., Walker, D. F., \& Singdahlsen, J. (1984). Play techniques with neurologically impaired preschoolers. American Journal of Occupational Therapy, 38(9), 603-612.

Spector, C. C. (1979). The Boehm Test of Basic Concepts: Exploring the results for cognitive deficits. Journal of Learning Disabilities, 12(8), 564-567.

Vargha-Khadem, F., Isaacs, E., Werf, S. V. D., Robb, S., \& Wilson, J. (1992). Development of intelligence and memory in children with hemiplegic cerebral palsy: The deleterious consequences of early seizures. Brain, 115, 315-329.

Vygotsky, L. S. (1976). Play and its role in the mental development of the child. In J. S. Bruner, Play: Its role in development and evolution (pp. 537-554). New York: Penguin Books.

Vygotsky, L. S. (1997). Obras Escogidas: Vol. V. Fundamentos de defectología. Madrid, España: Visor. (Original work published 1983)

Vygotsky, L. S. (1998). A formação social da mente (6. ed.). São Paulo, SP: Martins Fontes.

Vygotsky, L. S. (2001). A construção do pensamento e da linguagem. São Paulo, SP: Martins Fontes. (Original work published 1934) 